\title{
Investigations of influence of epoxy composite coatings on hydrodynamics and heat transfer processes of compact small diameter tube bundles
}

\author{
Valery Gorobets ${ }^{1}$, Yurii Bohdan ${ }^{2, *}$, Viktor Trokhaniak ${ }^{1}$, Ievgen Antypov ${ }^{1}$, and Alla Bohdan \\ ${ }^{1}$ Heat and Power Engineering Department, Education and Research Institute of Energetics, Automation and Energy Efficiency, National \\ University of Life and Environmental Sciences of Ukraine, Heroyiv Oborony st., 15, Kyiv, 03041, Ukraine \\ ${ }^{2}$ Vessel's Power Plant Operation Department, Marine Engineering Faculty, Kherson State Maritime Academy, Ushakova avenue, 20, \\ Kherson, 73000, Ukraine
}

\begin{abstract}
Tube bundles with cross flow heat carrier chart are widely used in many power systems due to their relatively simple design, low cost, low pressure drops, high efficiency etc. In order to exploitation these tube bundles in dirty and aggressive applications, protective coatings can be applied to the heat transfer surface to enhance effectiveness and minimize pollutant deposits. Protective coatings generally using for improving wear resistance, corrosion resistance, thermal conductivity to heat transfer surface and thermal insulation of frame surfaces of heat exchangers.

In this work physico-mechanical and thermophysical properties of heat conduct coating materials for heat transfer surface are investigated. Experimental and numerical investigations of hydrodynamics and heat transfer processes for compact small diameter tube bundles coated by epoxy composite with high thermal conductivity nanofillers are presented.

Experimental investigations of investigated tube bundles were carried out in open circuit section type wind tunnel of subsonic speeds.
\end{abstract}

\section{Introduction}

Nowadays, heat exchangers and their bundles are mostly made from metal [1]. This is due to the high thermal conductivity of the metal and structural strength. Various metals are used: copper, copper-nickel, titanium, brass, aluminum, stainless steel or less often low carbon steel. The main difference between these metals is the cost, thermal conductivity and corrosion resistance [2-4]. So low carbon steel is cheaper, but at the same time strongly corroded. Especially in corrosive environments (acidic, saline), heat exhangers elements made of low carbon steel are destroyed fairly quickly, which leads to corrosive deposits that reduce heat transfer and the tightness of the heat exchanger pathways [3]. In such conditions, special coatings can extend the life of the heat exchanger. To protect metal surfaces, in particular carbon steel, from saline moist environments, it is advisable to use a resistant coating. A number of different coatings for heat exchange surfaces are known [5-7]. One of the widely used is epoxy [8-11]. The basis of epoxy coatings is epoxy resin, which has high adhesion, cohesion and allows you to widely change its properties due to various fillers.

Epoxy coating, as the most economical and effective way to protect the surface, can be applied in many industries, transport, especially in regions with a maritime climate. The epoxy coating of heat exchangers elements gives long-term corrosion protection.

The number of works devoted to the study of the influence of such coatings on the processes of heat exchange and hydrodynamics occurring in heat exchangers, as well as their modeling, is not significant. These actually causes interest in this kind of research.

\section{Experimental set-up and modelling}

For heat transfer studies, aerodynamics resistance and the laws of flowing the gas stream of tube bundles conventialy used wind tunnel [12-14]. All experimental investigations carried out on the open circuit section type wind tunnel of subsonic speeds (Figure 1).

Wind tunnel consists of sections forming the flow passage (manifold (1), Witoshinsky nozzle (3), stabilizing section (5), test section (6), calming section (8), inserted-joint pipe (9)) and one axial fan (10) capacity of $11000 \mathrm{~m} 3 / \mathrm{h}$ and the pressure to $370 \mathrm{~Pa}$, which is driven three-phase induction motor $2.2 \mathrm{~kW}$.

Wind tunnel operates on the principle of the suction channel with dimensions of the test section of $300 \mathrm{~mm}$ by $300 \mathrm{~mm}$.

The air flow rate is regulated by the current frequency converter which regulates the speed of the

\footnotetext{
* Corresponding author: bohdanyurii09@gmail.com
} 
motor rotor and thus the fan impeller speed, changing the air flow.

For researches of tube bundle on the wind tunnel uses a number of measuring equipment for measuring the parameters of the processes of heat transfer and hydrodynamics. Also for researches of epoxy composite coatings uses measuring equipment for measuring the thickness of coatings, heat flux and heat transfer coefficient.

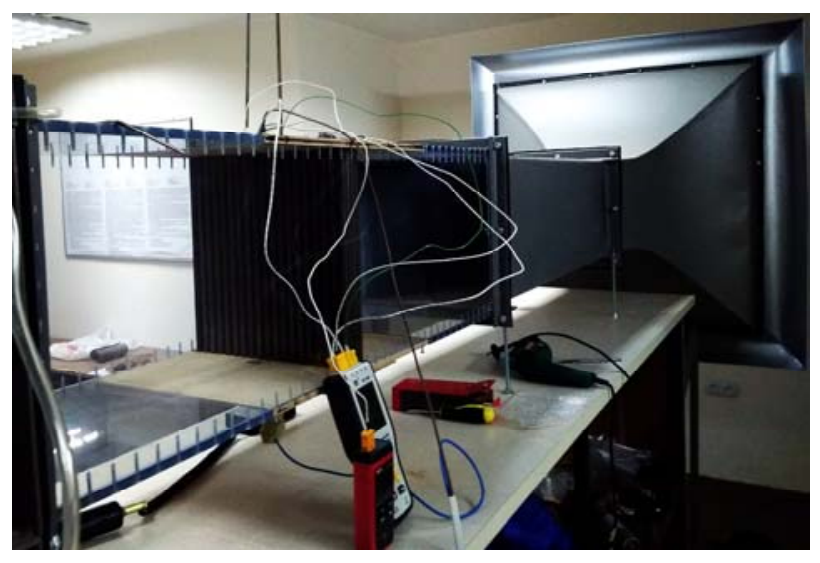

Fig. 1. General view of open circuit section type wind tunnel of subsonic speeds

List of measuring equipment:

1) Thermocouple thermometers Hti HT-9815,

2) Chrome-Copel thermocouples for temperature

measurement of the heat transfer surface on the gas side,

3) Heat-loss anemometer "AM-70",

4) Pitot-Prandtl (tube) gage,

5) Micromanometer "MMH-2400(5)" accuracy Class1.0,

6) Differential pressure flow meter "Testo 510",

7) Infrared camera FLIR E5,

8) Coating Thickness Gauge CM8811FN accuracy,

9) Vernier caliper Topex accuracy $0.01 \mathrm{~mm}$,

10) Installation for reproduction of heat flux "УBT-1" with accuracy error of $\pm 3 \%$

Investigated tube bundle consist of smooth tubes with diameter and thickness $-d_{1} \times \delta_{1}=0.010 \times 0.001 \mathrm{~m}$ coated by epoxy composite material with average thickness $\delta_{2}=0.0002 \mathrm{~m}$, tube material is steel, the equivalent diameter of the channel between rows of tubes is $D_{\text {chan.eq }}=0.009061 \mathrm{~m}$, length of tubes is $l=0.300 \mathrm{~m}$, equivalent diameter of casing is $D_{\text {cas.eq }}=0.300 \mathrm{~m}$, tube rows number is 19 with 4 tubes in each row.

Zukauskas and Ulinskas [12] recommended 4 rows for the heat transfer to be fully developed in a free tube bundle. One tube from bundle is calorific tube with electrical heater inside. The voltage at the terminals of the heater is set using a laboratory transformer, and the current is measured by an ammeter. Before measurements, heated the calorimetric tube for 60 minutes. The heat capasity of the electrical heater was constant end eqivalent to $26 \mathrm{~W}$.
The range of air velocity during experiments varied till 0 untill $7.0 \mathrm{~m} / \mathrm{s}$ by fan and using the frequency converter set the required air speed.

As a result of changes of the velocity of air, the range of values of the Reynolds Numbers Re varied till 0 untill 5000 .

To measure the temperature on the surface of the calorimetric tube along its length, 3 chromel-copel thermocouples are inserted. Thermocouples are arranged as follows, one in the middle, and the other two - at a distance of $15 \mathrm{~mm}$ from the tube ends.

During the main experiments measured: air flow; air temperature at the entrance to the test section and the mass-average temperature at the exit from it; static and total inlet pressure; total pressure at the outlet of the tube bundle; temperature of the calorimetric tube wall, the drop in static pressure over the length of the test section.

For the tube bundle numerical modeling of aerodrodynamics and heat transfer processes are conducted. The aim of these calculation is to obtain the fields of velocities, temperatures and pressures, and as well as obtaining of Nusselt numbers and Euler numbers in depending on Reynolds numbers.

Geometry of the investigated tube bundle with small diameter tubes coated by epoxy polymer has next geometrical characteristics: values of transversal and longitudinal step of tubes $S_{a} \times S_{b}=0.15 \times 0.10 \mathrm{~m}$, diameter of tubes with coating $d_{2}=0.0104 \mathrm{~m}$, number of tubes in row $i=4$, the tube bundle consist of $j=19$ rows, and the common number of tubes in bundle makes $z=76$.

The numerical modeling of processes of heat transfer and hydrodynamics in the tube bundle was conducted by means of ANSYS Fluent software. Mathematical twodimensional model of heat- and mass transfer processes, includes a system of Navier-Stokes equations, equation of energy transfer for convective flows $[15,16]$ and standard $k$ - $\varepsilon$ model of turbulence [17].

Equations of convective transfer of mass and energy shown as:

$$
\left.\begin{array}{c}
\frac{\partial \rho w_{x}}{\partial \tau}+w_{x} \frac{\partial \rho w_{x}}{\partial x}+w_{y} \frac{\partial \rho w_{x}}{\partial y}=-\frac{\partial p}{\partial x}+\frac{\partial}{\partial x}\left(\mu_{e f} \frac{\partial w_{x}}{\partial x}\right)+\frac{\partial}{\partial y}\left(\mu_{e f} \frac{\partial w_{x}}{\partial y}\right), \\
\frac{\partial \rho w_{y}}{\partial \tau}+w_{x} \frac{\partial \rho w_{y}}{\partial x}+w_{y} \frac{\partial \rho w_{y}}{\partial y}=-\frac{\partial p}{\partial y}+\frac{\partial}{\partial x}\left(\mu_{e f} \frac{\partial w_{y}}{\partial x}\right)+\frac{\partial}{\partial y}\left(\mu_{e f} \frac{\partial w_{y}}{\partial y}\right)
\end{array}\right\}
$$

A two-parameter standard $k-\varepsilon$ model that consists of two differential equations of kinetic energy transfer and velocity of dissipation is used for the modeling of turbulent flow.

$$
\begin{aligned}
& \frac{\partial \rho k}{\partial \tau}+w_{x} \frac{\partial \rho k}{\partial x}+w_{y} \frac{\partial \rho k}{\partial y}=\frac{\partial}{\partial x}\left(\frac{\mu_{e f}}{\sigma_{k}} \frac{\partial k}{\partial x}\right)+\frac{\partial}{\partial y}\left(\frac{\mu_{e f}}{\sigma_{k}} \frac{\partial k}{\partial y}\right)+G_{k}-\rho \varepsilon, \\
& \frac{\partial \rho \varepsilon}{\partial \tau}+w_{x} \frac{\partial \rho \varepsilon}{\partial x}+w_{y} \frac{\partial \rho \varepsilon}{\partial y}=\frac{\partial}{\partial x}\left(\frac{\mu_{e f}}{\sigma_{\varepsilon}} \frac{\partial \varepsilon}{\partial x}\right)+\frac{\partial}{\partial y}\left(\frac{\mu_{e f}}{\sigma_{\varepsilon}} \frac{\partial \varepsilon}{\partial y}\right)+c_{\varepsilon 1} G_{k} \frac{\varepsilon}{k}-c_{\varepsilon 2} \rho \frac{\varepsilon^{2}}{k}, \\
& \text { where } \mu_{e f}=\mu+\mu_{t}, \lambda_{e f}=\lambda+\lambda_{t}, \mu_{t}=\frac{c_{\mu} \rho k^{2}}{\varepsilon}, G_{k}=\mu+\frac{\partial w_{x}}{\partial x_{i}}\left(\frac{\partial w_{j}}{\partial x_{i}}+\frac{\partial w_{i}}{\partial x_{j}}\right) \\
& c_{\mu}=0.09, c_{\varepsilon 1}=1.44, c_{\varepsilon 2}=1.92, \sigma_{k}=1, \sigma_{\varepsilon}=1.3 .
\end{aligned}
$$


Next boundary conditions were use for modeling: $w_{i}(\tau=0)=0, w_{i}(x=0)=w_{i n}, w_{i}\left(x_{i}=x_{w}\right)=0,\left.t\right|_{s}=\left.t_{w}\right|_{s}$

Numerical calculations in the investigated tube bundle is carried out with the Reynolds number $\mathrm{Re}=3981$. As heat carrier is used air with a temperature at the inlet $19.5^{\circ} \mathrm{C}$, which flow in the channels of the tube bundle. The temperature of the wall of the calorific tube was assumed constant.

Material of the pipe "Steel". All pipes have a polymeric coating with thickness $0.2 \mathrm{~mm}$. On the $3 \mathrm{rd}$ calorific tube, the boundary condition "wall_coupled_3L" and "wall_coupled_3R".

In the numerical calculation of the problems of hydrodynamics and heat transfer, the finite element method is used. Construction of the mesh was carried out in the mesh generator ANSYS Meshing on the basis of the Workbench platform. When constructing a mesh for the tube bundle of all models, local mesh control is used. Construction of a quadrilateral dominant mesh (Figure 2) using the design of a boundary layer by the method of "Total Thickness", thickness of the first layer $5 \cdot 10^{-5} \mathrm{~m}$ with the number of 6 layers (Figure 3).

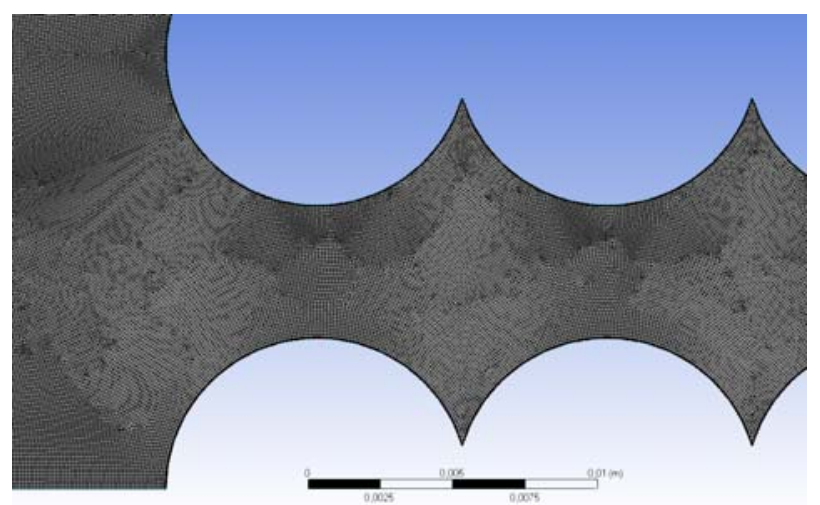

Fig. 2. Construction of a quadrilateral dominant mesh

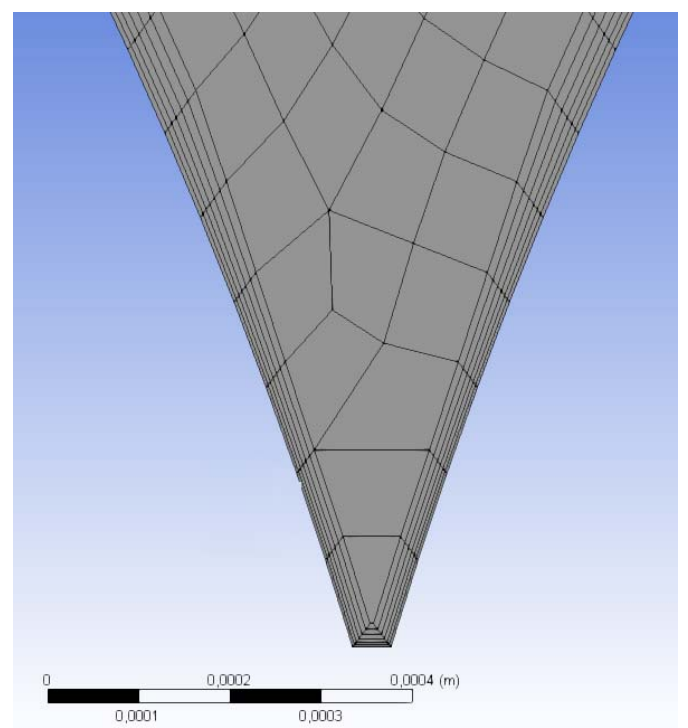

Fig. 3. Design of a of a boundary layer by the method of "Total Thickness"
The mesh orthogonal quality is 0.567 . The minimum size of the element is $1 \cdot 10^{-6} \mathrm{~m}$. The maximum dimension of the face is $1 \cdot 10^{-4} \mathrm{~m}$. The number of elements is about 245 thousand.

As a coating for researches, an epoxy diane oligomer “ЭД-20” (GOST 10587-84) was selected. Nano dispersed carbon black "PowCarbon 2419G" (CAS NO.:1333-86-4, EINECS NO.:215-609-9) manufactured by "Black Diamond Material Science Co., Ltd.", China, was used as a filler. The particle size of the powder is determined using the method of electron microscopy and is $24 \pm 2 \mathrm{~nm}$.

Polyethylenepolyamine (PEPA) (TU 6-05-241-20278), which allows curing of materials at room temperature, is used for crosslinking epoxy compositions. It is known that PEPA is a low molecular weight polymer, which consists of the following monomer units: [-CH2-CH2-NH-]n. The hardener was injected into a composition in an amount of 10 parts by weight per 100 parts by weight of epoxy oligomer “ЭД20 ".

Measurement of the thermal conductivity coefficient of the test specimen (epoxy resin $40 \times 40 \times 5,7 \mathrm{~mm}$ ) is carried out by the method of a hot protected plate, which lies in creation a temperature difference between two surfaces of a test specimen at a stationary thermal mode. As a results of the measurements identified temperature difference, the density of the heat flux through the specimen, and the thickness of this specimen, calculated the heat transfer coefficient of the specimen.

Specimen is placed in the measuring chamber of the installation "УBT-1", as shown in the figure 4, while in the centers of the working surfaces of the specimen arranged junctions of tape differential thermocouple of thickness $0.05 \ldots 0.07 \mathrm{~mm}$, which are mounted in thin silicone gaskets, which provides pressing of the thermocouple junctions to the surface of the specimen and minimizes the possible microscopic surface roughness of the specimen.

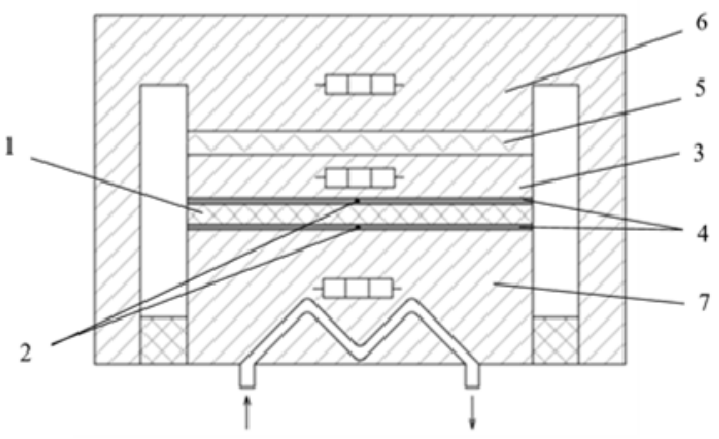

Fig. 4. Scheme of spesimen arrangement inside messurment chamber of installation "УBT-1": 1 - specimen; 2 - junctions of tape differential thermocouple; 3 - main heater; 4 - silicon gasket; 5 - control sensor of heat flux; 6 - protective shield combined with a protective heater; 7 - adjastable temperature cooler

The "УBT-1" unit has a thermal mode for generating heat flux density in the range of $800 \ldots 1000 \mathrm{~W} / \mathrm{m}^{2}$, and the temperature of the heater and the cooler is 
successively set, so that the temperature difference on the working surfaces of the test specimen is $15 \ldots 20 \mathrm{~K}$, and the average temperature value of the specimen meets the required temperature of measurement.

After establishing a stationary thermal mode, the value of the difference in temperature, heat flux through the specimen was recorded.

The value of the coefficient of thermal conductivity of the test specimen at a certain temperature is calculated by the formula:

$$
\lambda(T)=h \cdot Q \cdot(A \cdot \Delta T)^{-1}
$$

Infrared camera FLIR E5 was used to determine the average temperature on the tube surface and the uniform distribution of temperatures.

\section{Results and discussions}

The distribution of the velocity vectors in the tube bundle is shown in Figure 5.

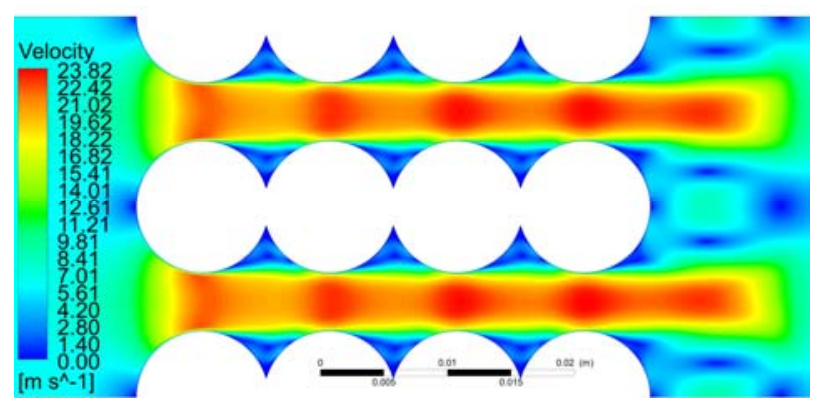

Fig. 5. Velocity in the channels of tube bundle, $\mathrm{m} / \mathrm{s}$ $(\mathrm{Re}=3981)$

The value of the average velocity of air in the narrowest cross section of the channel is $21 \pm 2 \mathrm{~m} / \mathrm{s}$ (Figure 5).

In Figure 6 shows the temperature distribution in the channels where air temperature at the inlet and outlet the same and equal $19{ }^{\circ} \mathrm{C}$. Which indicates the removal of heat from the calorimetric tube at $\mathrm{Re}=1270$.

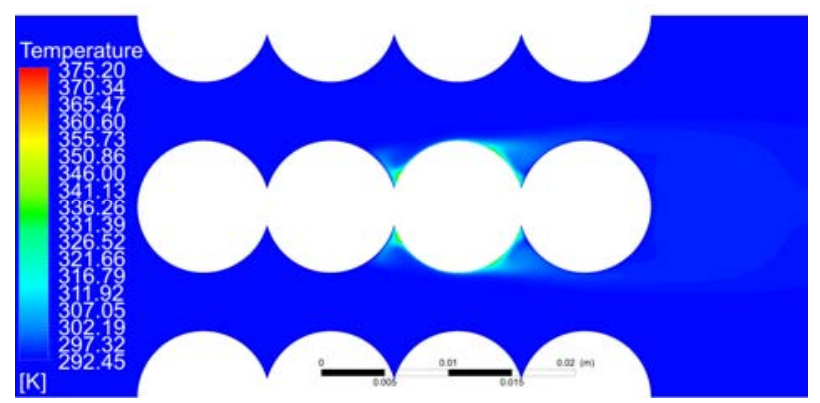

Fig. 6. Change of temperature in the channels of tube bundle, ${ }^{\circ} \mathrm{C}(\mathrm{Re}=1270)$

Experimental and numerical results for the compact tube bundle with the absence of gaps between adjacent tubes of longitudinal rows were obtained in article [18].
Results of investigations of the flow and heat transfer in the coated and non coated tube bundle were estimated by comparing the obtained experimental data (wind tunnel) with the results of numerical simulation. The results of the researches are presented in the form of graphical dependences in Figures 7, 8 for Reynolds numbers in the range $\mathrm{Re}=0 \div 5000$ and Prandtls number $\operatorname{Pr}=0.73$.

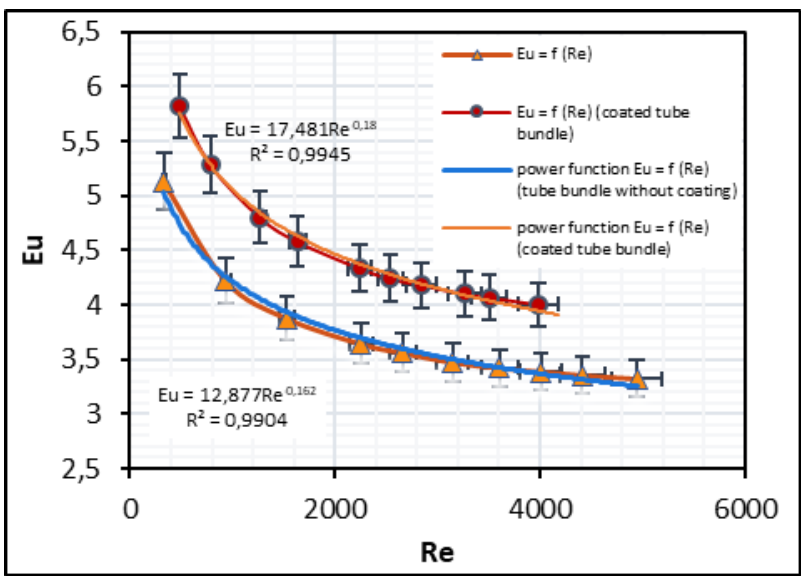

Fig. 7. Dependence of the Euler number Eu of air flow on Reynolds number Re for coated and non coated tube bundle

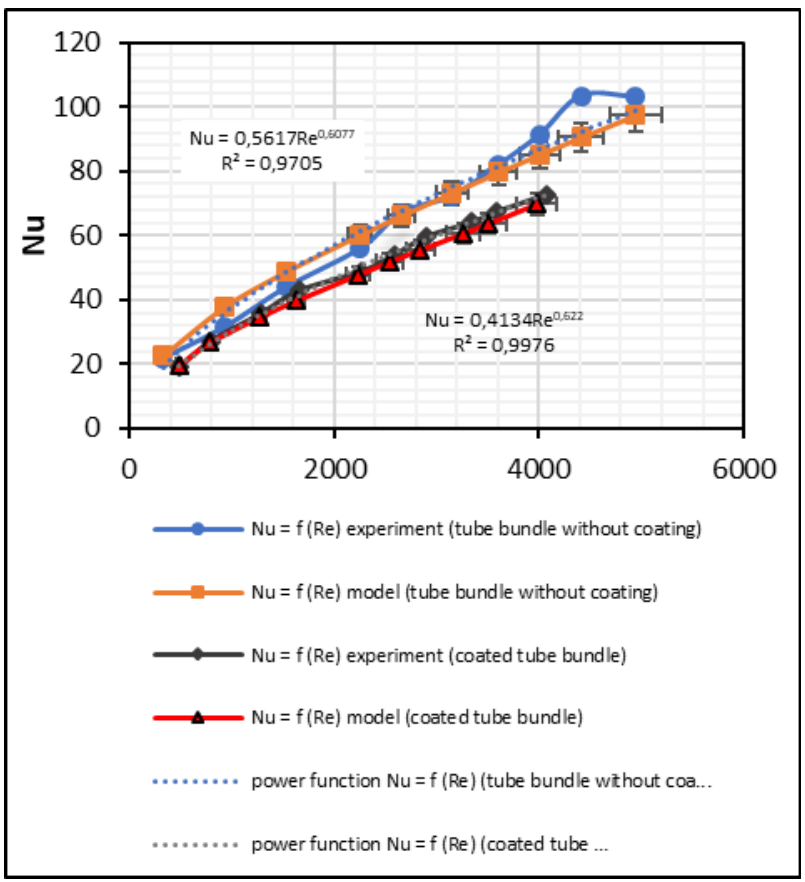

Fig. 8. Dependences of average Nusselt number $\bar{N} u$ on Reynolds number Re of non coated and coated tube bundles

In Figure 8 showed increasing of Euler number of coated tube bundle due to reducing of equivalent diameter of channel between rows of tubes. In Figure 9 compared the experimentally and numerically determined dependences of Nusselt number averaged over the surface $\bar{N} u$ on Reynolds number Re of non- 
coated tube bundle with the same dependences of coated tube bundle. The comparison shows that for the same values of Reynolds number, the intensity of heat transfer for a compact non coated bundle with small diameter tubes is almost on $18 \%$ higher than intensity of heat transfer on the surface of the coated tube bundle. That's mean coatings makes some resistance and the value of this resistance depends on it thickness and thermal conductivity.

\section{Conclusions}

1. Experimental and numerical investigations, dependencies of the Nusselt number $\mathrm{Nu}$ and Euler number $\mathrm{Eu}$ on the Reynolds number $\mathrm{Re}$ in the range of $0<\operatorname{Re}<5000$ of the investigated 19th-row tube bundle non coated and coated were obtained.

2. Tube bundles coating made from epoxy composite material allows to obtain tube corrosive resistance at the same time not significantly reduced coefficient of heat transfer and hydraulic resistance of the investigated tube bundle.

3. Thermal conductivity of used pure epoxy resin and epoxy composite coatings were obtained. Appropriate concentration, thermo-physical and mechanical properties of fillers this is the mainstream to improve coating thermal conductivity and its strength.

\section{References}

1. G.F. Hewitt, Heat Exchanger Design Handbook (Begell House, New York, 2008)

2. P. Rodriguez, Proceedings of the 3rd international conference on heat exchangers, boilers and pressure vessels (HEB-97), Alexandria, Egypt, pp. 59-72 (1997)

3. C. Ezgi, Journal of Naval Science and Engineering, 10(1), pp. 1-12 (2014)

4. G. Grimvall, Thermophysical properties of materials, Amsterdam, Elsevier, 1999)

5. R.P. Lee, Corrosion, 14(4), pp. 41-42 (1958)

6. D.J. Kukulka, P. Leising, Chemical Engineering Transactions, 18, pp. 339-344 (2009)

7. S. Pungaiya, C. Kailasanathan, Int. J. Mech. Eng. Rob. Res, 7(5), pp. 458-465 (2018)

8. M.A. Vadivelu, C. Ramesh Kumar, Girish M. Joshi, Composite Interfaces, pp. 1-26 (2016)

9. I.A. Tsekmes, IEEE, International Conference on Solid Dielectrics, Bologna, Italy, pp. 678-681 (2013)

10. W. Park, K. Choi, K. Lafdi, C. Yu, Trans. ASME. J. Heat Transfer, 134(4), pp. 041302-1 - 41302-7 (2012)

11. E.A. Nikolaeva, A.N. Timofeev, K.V. Mikhaylovskiy, Informacionno-technologicheskij vestnik, 15(1), pp. 156-168 (2018)
12. A. Zhukauskas, R. Ulinskas, Heat transfer of cross flow tube bundles (Mokslas, Vilnius, 1986)

13. J.C. Lerner, Wind Tunnels and Experimental Fluid Dynamics Research, (InTech, 2011)

14. S. Okamoto, Wind Tunnels (InTech, 2011)

15. H. Schlichting, Boundary-Layer Theory, $7^{\text {th }}$ edition, (McGraw-Hill, New York, 1979)

16. D. Taler, Numerical Modelling and Experimental Testing of Heat Exchangers (Springer, BerlinHeildelberg, 2019)

17. ANSYS FLUENT Theory Guide. Release 14. ANSYS, Inc. Southpointe 275 Technology Drive Canonsburg, PA 15317, 2011

18. V. Gorobets, Yu. Bohdan, V. Trokhaniak, I. Antypov, Appl. Therm. Eng., 151, pp. 46-54 (2019) 